\title{
FORMAÇÃO DE EDUCADORES AMBIENTAIS NA TESSITURA DE UM GRUPO DE PESQUISA
}

\author{
Raphael Alves Feitosa ${ }^{1}$ \\ João Batista de Albuquerque Figueiredo ${ }^{2}$
}

Resumo: $\mathrm{O}$ artigo analisa o que estudantes pesquisadores pertencentes a um grupo de pesquisa compreendem sobre as atividades desenvolvidas no grupo, bem como investiga as contribuições da referida confraria para a formação de educadores ambientais. Os resultados apresentados na pesquisa indicam que o grupo de pesquisa foi visto pelos seus membros como uma possibilidade de formação humana colaborativa que estimulou a criatividade, a diversidade de pontos de vista e os laços de companheirismo, de parceria. Os partícipes conceberam o grupo como um lócus de aprofundamento de saberes individuais e coletivos, criando um campo de possibilidades formativas, de costura de saberes parceiros.

Palavras-chave: Educadores ambientais. Grupo de pesquisa. Companheiros de ofício.

\section{EDUCATION OF ENVIRONMENTAL EDUCATORS IN THE WEAVING OF A RESEARCH GROUP}

\begin{abstract}
The paper examines what student researchers from a research group understand about the activities of the group, as well as investigates the contributions of that brotherhood for the education of environmental educators. The results presented in this research indicate that the research group was seen by its members as a possibility of collaborative human formation which stimulated creativity, diversity of views and the bonds of fellowship, of partnership. The participants conceived the group as a locus for the development of individual and collective knowledge, creating a field of educational possibilities in which knowledge is woven and shared.
\end{abstract}

Keywords: Environmental educators. Research group. Workfellows.

\section{FORMACIÓN DE EDUCADORES AMBIENTALES EN LA TESITURA DE UN GRUPO DE INVESTIGACIÓN}

Resumen: El artículo analiza lo que estudiantes investigadores pertenecientes a un grupo de investigación comprenden sobre las actividades desarrolladas en el grupo, así como investiga las contribuciones de la referida cofradía para la formación de educadores ambientales. Los resultados presentados en la investigación indican que el grupo de investigación fue visto por sus miembros como una posibilidad de formación humana colaborativa que estimuló la creatividad, la diversidad de puntos de vista y los lazos de compañerismo, de colaboración. Los partícipes concibieron el grupo como un locus de perfeccionamiento de saberes individuales y colectivos, creando un campo de posibilidades formativas, de costura de saberes colaboradores.

\footnotetext{
${ }^{1}$ Doutorando do Programa de Pós-Graduação em Educação da Universidade Federal do Ceará (UFC). Professor do Instituto Federal de Educação, Ciência e Tecnologia do Ceará (IFCE), Fortaleza, Brasil, raphael.feitosa@ifce.edu.br

2 Professor Doutor da Faculdade de Educação, do Programa de Pós-Graduação em Educação Brasileira e do Departamento de teoria e Prática de Ensino - DTPE, da Universidade Federal do Ceará (UFC),Fortaleza, Brasil, joaofigueiredo@hotmail.com
} 
Palabras clave:: Educadores ambientales. Grupo de investigación. Compañeros de oficio.

\section{Introdução}

Ao adotarmos como premissa a leitura de que a educação é parte integrante e essencial para se possibilitar uma mudança socioambiental, consideramos que é relevante pensar em estratégias formativas para os educadores ambientais, no plural. Por "educador ambiental" entendemos aquele(a) que exerce alguma atividade sistematizada de educação ambiental, bem como aquele(a) cuja profissão lhe possibilita atuar na dimensão educativa presente nas relações culturais, numa perspectiva ambiental. Nesse sentido, Kawasaki, Matos e Motokane (2006) consideram que existe uma diversidade de profissionais que podem ser ligados a essa perspectiva.

Sobre a formação desses profissionais, Tozoni-Reis (2002) indica que durante muito tempo os cursos universitários que se relacionavam à temática ambiental estavam amplamente dominados por uma tendência naturalística, cuja característica primordial é a busca pela conservação dos ambientes naturais e a (re)inserção do ser humano na dinâmica ecológica. Contudo, ela acredita que, durante os últimos anos, a universidade vem abrindo espaço, ainda que de forma tímida, para outros paradigmas. Segundo a autora (2002, p. 86),

[...] a formação dos educadores ambientais nos cursos de graduação das universidades é fundamentada por diferentes formulações teóricas, que podem indicar tentativas de superação dos paradigmas atuais, tradicionais, de interpretação da realidade.

Diante dessa perspectiva, acreditamos que há espaço e pertinência para a formulação de novas propostas formativas para os(as) educadores(as) ambientais. A ideia central que apresentamos é que o aprimoramento da profissionalidade desses pode ser favorecido e potencializado pela participação em grupos de pesquisa sobre educação ambiental (EA).

A relevância do estudo sobre esses grupos pode ser referendada quando se percebe que, "na última década do século XX, houve uma expressiva expansão dos grupos de pesquisa, que continuou nos anos 2000" (MOCELIN, 2009, p. 37). Segundo esse autor, tal crescimento vincula-se ao acréscimo da concorrência no meio acadêmico e à organização de alianças entre os pesquisadores, formando grupos de pesquisa, com o intuito de participarem de forma mais direta da distribuição de recursos materiais e simbólicos, além de tentarem ocupar espaços de maior destaque na comunidade cientifica. Em nosso entendimento, em menor escala, há uma ampliação do reconhecimento da premência de novos paradigmas que contemplam a compreensão do coletivo, dos grupos como algo que agrega e aprimora o campo.

Por exemplo, Pereira et al. (2012) acreditam que o grupo de pesquisa representa uma oportunidade para seus integrantes compartilharem saberes teóricos e práticos e para estimular estudantes e professores(as) à criação e aos estudos, cujo alvo está na busca de soluções para problemas identificados em determinado contexto.

Diante dessa perspectiva, vários autores(as), das mais diversas áreas do conhecimento, buscam compreender os grupos de pesquisa e suas potencialidades formativas. No campo das ciências agrárias, Ribeiro (2007) apresenta alguns relatos de experiências sobre grupos de pesquisa. $\mathrm{Na}$ área de administração, temos o trabalho de Rapini (2007), que analisa a interação de universidades e empresas no Brasil. Em psicologia, Pinheiro (2005) destaca os grupos de pesquisa em Psicologia Ambiental. Na área de saúde destacam-se os trabalhos de Prado e Sayd (2004), que fazem um levantamento dos grupos de investigadores na área de envelhecimento, e de Krahl e colaboradores (2009), que indicam a importância da participação de acadêmicos de enfermagem num grupo de pesquisa, apontando

[...] essa participação como uma oportunidade para o entrelaçamento dos conhecimentos teóricos com a prática assistencial e que ainda se constitui em um importante instrumento para o desenvolvimento do seu poder criativo na medida em que propicia a busca de soluções para os problemas encontrados na realidade (KRAHL et al., 2009, p. 147). 
No campo da educação brasileira, encontramos exemplos de trabalhos sobre o tema. Fagagnoli e colaboradores (2008) demonstraram que os estudantes partícipes de um grupo de pesquisa na área de educação física obtiveram melhores desempenhos ao final da graduação e da pós-graduação se comparados aos estudantes que não participavam de nenhum grupo. Segundo os autores, os aspectos colaborativos de estudo-pesquisa e os laços desenvolvidos pelos integrantes foram relevantes para a sua formação, "o que acabou por tornar a participação no Grupo um divisor de águas para esses acadêmicos" (p. 71). Hillebrand (2001) apresenta o estudo em grupo como um espaço-tempo que permite aos docentes de escolas de ensino básico trocar vivências, compartilhar conhecimentos de acordo com suas necessidades, bem como potencializar aprendizagem e ressignificação da prática e dos saberes de cada profissional presente no grupo. Já na área de educação matemática, Baldino (2001) mostra que os grupos de pesquisa-ação ${ }^{3}$ são uma intervenção discursiva na academia.

Em outros países do mundo, também há o interesse de pesquisadores em educação pela investigação de grupos de estudo/pesquisa. Em Portugal, por exemplo, Ricardo (2004) mostra que um grupo de estudos (GEPDES) composto por professores secundaristas, ao estender e fortificar os laços de companheirismo entre os integrantes, criou condições de ampliar a luta política dentro das escolas, gerando um lócus de resistência ao regime antidemocrático que ocorreu naquele país nos anos 1960.

Apesar de haver publicações sobre a formação humana dentro de grupos de pesquisa e estudo em algumas áreas da ciência, incluindo a educação, no campo específico da EA essa temática ainda é escassa. Tal constatação torna a investigação sobre a formação colaborativa ainda mais relevante.

Seguindo essa perspectiva formativa, iremos analisar os processos em um grupo de pesquisa da Universidade Federal do Ceará (UFC) chamado de Grupo de Estudos e Pesquisas em Educação Ambiental Dialógica, Perspectiva Eco-Relacional e Educação Popular Freireana GEAD. O grupo, formado em 2005, conta atualmente com 20 (vinte) integrantes, sendo 4 (quatro) professores pesquisadores e 16 (dezesseis) estudantes dos mais diversos níveis (Graduação, Mestrado e Doutorado). Fazem parte do grupo estudantes e pesquisadores oriundos de várias áreas da academia, como, por exemplo: pedagogia, educação física, ciências biológicas e da terra, ciências sociais, história, geografia, letras e psicologia.

Diante da perspectiva formativa dentro de uma parceria coletiva e colaborativa, indagamos: como os integrantes do grupo de pesquisa/estudo GEAD concebem as experiências formativas vivenciadas no grupo? Este artigo busca responder a esse questionamento. Assim, o objetivo deste texto é analisar o que os estudantes pesquisadores compreendem sobre as atividades experienciadas no grupo, bem como investigar as contribuições da referida confraria para a formação de educadores(as) ambientais.

Para tanto, este trabalho está dividido em três subitens, a saber: (1) colorindo uma mandala; (2) procedimentos metodológicos de investigação; (3) florescer de novas perspectivas. Em colorindo uma mandala, trazemos os referenciais teóricos e apresentamos nossa compreensão sobre a educação ambiental (EA), tendo como base a EA crítica (CARVALHO, 2001; FIGUEIREDO, 2007; LOUREIRO, 2006). Nessa parte, também destacamos as possibilidades formativas que as Associações de Companheiros de Ofício (FEITOSA; LEITE, 2011, 2012) podem trazer para a formação de educadores ambientais. Em seguida, apresentamos o processo metodológico de coleta e análise de dados. Por fim, no subitem florescer de novas perspectivas, damos $\mathrm{VOZ}$ ao grupo de aprendizes ensinantes ${ }^{4}$ e explicitamos as concepções dos participantes do

\footnotetext{
3 Para Baldino (2001), o vocábulo "pesquisa-ação" representa a ideia de que não existem pesquisas sem ação, apenas existem pesquisas que desconhecem sua própria ação.

${ }^{4}$ Recorrendo à concepção de aprendizado em cooperação, postulada por Feitosa e Leite (2011) para as Associações de Companheiros de Ofício, na qual os aprendizes também são ensinantes e os ensinantes também são aprendizes, tal como Freire (1983) nos informa.
} 
referido grupo buscando uma articulação entre o aprendizado da educação ambiental e o processo colaborativo que ocorre numa Associação de Companheiros de Ofício.

\section{Colorindo uma mandala: os referencias teóricos}

A escolha da mandala como figura representativa das nossas perspectivas teóricas se deve ao fato de que ela porta um significado pedagógico metafórico, a saber: o termo "mandala" está relacionado ao círculo, uma representação geométrica da dinâmica relação entre o ser humano e o universo, entre o micro e o macrocosmo (FRANCHI, 2002). A síntese de sua significação cabe na etimologia da palavra mandala, que vem do sânscrito e significa círculo. Ela é um diagrama simbólico usado como instrumento para meditação, uma vez que atua como uma representação do cosmo, um ponto de união das forças universais com as terrenas.

As mandalas são constituídas por uma imagem arredondada miscigenada por um padrão de forma que se repete simetricamente em torno de um ponto central. O contorno circular de uma mandala parece expressar o divino e o mundano, a união e a desagregação. A mandala representa "uma imagem sintética do dualismo entre diferenciação e unificação, variedade e unidade, exterioridade e interioridade, diversidade e concentração" (RAMOS, 2006, p. 13). Em nosso entendimento, a mandala reintegra, reunifica, reúne, tal qual um grupo que associa indivíduos a um campo de integração que os unifica em torno de propósitos comuns, potência para o indivíduo e grupo no ir para além do que é agora. Empodera o indivíduo-grupo.

Trazendo essa metáfora para o campo da educação, Feitosa e Leite (2011) indicam que, da mesma forma que visa uma união entre os contraditórios do universo espiritual e mundano, a mandala pode representar pedagogicamente a construção inicial de uma síntese dialética de diferentes aspectos contraditórios em que se conectam os seres humanos envolvidos num processo educativo.

No caso desta pesquisa, a mandala se relaciona à possibilidade de reintegração entre teoria e prática, ensino e pesquisa, através da práxis transformadora, bem como representa uma articulação entre a subjetividade e a coletividade no grupo de pesquisa. Assim, a mandala é, num sentido metafórico, uma forma conectiva e uma síntese de múltiplas relações, de saberes parceiros unidos num diálogo teórico-prático que é, ao mesmo tempo, harmônico e desarmônico, visível e invisível, essência e aparência.

Com base nessa perspectiva mandálica, a seguir explicitamos nossas visões sobre a educação ambiental (EA) e sobre a formação de educadores ambientais através de uma Associação de Companheiros de Ofício.

\section{Educação Ambiental: as tonalidades amarelas, azuis e vermelhas da mandala}

No que diz respeito à EA, Carvalho (2001) afirma que existe uma vasta diversidade de concepções que compartilham esse mesmo vocábulo. Desta feita, sabendo que existem várias correntes de EA, é preciso esclarecer nosso ponto de vista. Para iluminar essa diversidade de propostas educativas, recorremos aos trabalhos de Figueiredo (2007), Carvalho (2001) e Loureiro (2006).

Figueiredo (2007) classifica as visões de EA em dois grupos: a crítica e a não crítica. Para o autor, a EA Crítica tem inspiração no campo teórico das teorias críticas, desenvolvidas a partir da década de 1970. Assim, a ressignificação da educação ambiental como "crítica" se relaciona com a necessidade de diferenciar uma ação pedagógica capaz de colaborar para a transformação de uma realidade que, historicamente, se coloca em uma grave crise ambiental, portanto, social, política e cultural.

Essa linha crítica está fortemente identificada com as ideias de autores que tomaram como foco a problemática educacional, o currículo e as relações entre poder e educação. Apesar de não se ter uma uniformidade entre as concepções e os trabalhos dos autores dessa linha, eles 
apresentam em comum essa crítica ao tradicionalismo educativo, coligado pelo início da crítica marxista às teorias tradicionais da educação (FOSTER, 2005).

Carvalho (2001) também compreende que existem várias formas de se pensar a EA. A autora classifica as tendências da área em dois grupos, os quais, grosso modo, representam dois pontos de embate da EA: a comportamental e a popular. A primeira está ligada ao ponto de vista conservador e enfatiza o caráter da educação como agente transmissor dos saberes sobre o meio ambiente e "indutor da mudança dos hábitos e comportamentos considerados predatórios em hábitos e comportamentos tidos como compatíveis com a preservação dos recursos naturais" (CARVALHO, 2001, p. 46). Já a segunda representa uma concepção progressista, que visualiza o processo educativo como um ato político, ou seja, considera que a educação ambiental faz parte de prática social de formação humana. A educação ambiental popular, diz a autora, converge para as percepções mais críticas da pedagogia, com o pressuposto de que a meta basilar da educação é a formação de "sujeitos" políticos, capazes de transformar a sociedade. Os autores epistêmicos, atores/autores sociais, a que se destina essa educação são os "sujeitos" históricos, inseridos em determinada perspectiva social, política e cultural.

Ainda no sentido de identificar as diferentes propostas de EA existentes na práxis educativa, trazemos para este diálogo a contribuição de Loureiro (2006). O autor identifica dois blocos que dão ênfases opostas para a EA: um denominado conservador (comportamentalista) e outro chamado de emancipatório (transformador ou crítico). No primeiro temos como características principais a compreensão naturalista e conservacionista da crise ambiental, a visão de que a educação deve ser entendida em sua dimensão individual, baseada em vivências práticas, e a despolitização do fazer educativo ambiental. No segundo bloco temos como aspectos dominantes a politização da problemática ambiental, o entendimento de que a participação social ativa é uma prática indissociável da EA e a visão indissociável dos processos interecorrelacionados, a saber: "produção e consumo; ética, tecnologia e contexto sócio-histórico; interesses privados e interesses públicos" (LOUREIRO, 2006, p. 134).

Após discorremos sobre algumas propostas distintivas de EA, retomamos a metáfora da mandala e tentaremos dar cores a nossa proposta teórica. Considerando que funciona como uma forma conectiva dos diversos aspectos da educação e é uma síntese de múltiplas relações socioculturais, a mandala deve ter uma profusão de cores marcantes, em especial o verde (mistura entre o amarelo e o azul) e o vermelho.

A cor verde da nossa mandala teórica indica nossa relação com uma educação ambiental que visa à conservação do mundo natural, incluindo os entes vivos e os não vivos. Contudo, é preciso ir além desses tons, caso contrário nossa mandala correria o risco de ficar presa numa forma monocromática de despolitização e de individualidade, pois esquecemos que o verde decorre de uma mistura. Assim, também trazemos as cores rubras do movimento marxista da educação, representado pelas formas mandálicas das teorias pedagógicas críticas. Com estas últimas é possível adensar nossa proposta teórica em busca de uma práxis revolucionária que vá além do conservacionismo e que congregue os ideais de justiça socioambiental, equidade, democracia, respeito à sabedoria popular e de luta por um mundo sustentável e comunista. Os tons vermelhos de nossa mandala relembram a proposição marxiana de relação metabólica de indissociabilidade entre ser humano e natureza:

Este comunismo é, enquanto naturalismo consumado $=$ humanismo, enquanto humanismo consumado = naturalismo. Ele é a verdadeira dissolução (Auflösung) do antagonismo do homem com a natureza e com o homem. (MARX, 2004, p. 105).

\section{Associações de Companheiros de Ofício: aprendendo a formar educadores com cores e formas mandálicas}

Devemos manter em mente a urgente necessidade de se discutir a formação inicial e continuada de educadores ambientais (CARVALHO, 2001). Tentando antever uma possibilidade 
formativa, Feitosa e Leite $(2011,2012)$, apoiados na teoria de aprendizagem colaborativa de De Masi (2007) e de Queiroz (2001), propõem uma formação baseada nos ateliês artísticos, locais que podem aliar teoria e prática através de uma práxis criativa e transformadora. Feitosa e Leite (2012) trazem como referência o processo de formação dos artistas (atores, músicos, dançarinos, escultores etc.). Nesse campo, o aprendizado da profissão tem a seguinte característica: "[...] a prática é realizada junto com a teoria, [e] ambas se influenciam mutuamente; não há prática sem teoria, assim como não há teoria sem prática" (FEITOSA; LEITE, 2012, p. 38). Assim também se pronunciam Freire (1983) e Figueiredo (2007).

Nesse modelo, o educador, ao refletir com seus pares, cria uma nova realidade, experimentando, inventando e reconstruindo através do diálogo que estabelece com essa mesma realidade. Dessa forma, compreendemos que essa é uma forma interessante para pensarmos a formação, inicial e continuada, de educadores ambientais. Seguindo essa perspectiva, a formação humana se daria "num espaço-tempo marcado, preponderantemente, por uma inter-relação coletiva entre os sujeitos participantes, a qual chamamos de Associação de Companheiros de Ofício" (FEITOSA; LEITE, 2012, p. 40). Figueiredo (2007), por sua vez, denomina isso grupo aprendente.

Tal modo de formação é uma releitura crítica das guildas ${ }^{5}$, isto é, corporações medievais de ofícios. Ela conjetura a existência de diferentes níveis desses saberes entre os companheiros da associação. Os mais experientes possuem uma série de saberes que são construídos na prática cotidiana (saberes da experiência), ao passo que os noviços estão em busca do desenvolvimento desses saberes práticos.

Feitosa e Leite (2011) sugerem que a própria formação de educadores pode funcionar nessa perspectiva colaborativa, mostrando indícios de que é possível vislumbrar o trabalho docente como uma espécie de educação artística, feita dentro de corporações de aprendizes ensinantes. Para aprofundar tal possibilidade, os autores epistêmicos trazem como categorias fundantes das Associações de Companheiros de Ofício as seguintes características: trabalho interdisciplinar; professor artista; colaboração; reflexão; engajamento ${ }^{6}$; transformação social.

Essa forma de pensar a formação humana parece ser de grande aproveitamento para a educação ambiental, uma vez que denota a relevância de compartilhar saberes entre os educadores artistas mais experientes (artesão mestre) e os iniciantes. Assim, com base nessa visão, defendemos a existência de uma interação dos aprendizes com os mestres mais experientes.

Quando relacionamos a teoria da formação do professor artista (FEITOSA; LEITE, 2012) com a proposição de educação continuada em um grupo de estudos (HILLEBRAND, 2001), percebemos que os grupos de pesquisa/estudo podem ser locais permeados pelos processos de ensino-aprendizagem colaborativo. Isso pode permitir uma ampla gama de possibilidades para a formação inicial e continuada de educadores ambientais, como num movimento artístico crítico-reflexivo que gera cores e formas mandálicas, de colaboração, parceria e aprendizado mútuo.

\section{Procedimento metodológico de investigação}

A presente investigação insere-se em uma abordagem qualitativa de pesquisa, já que reconhece a dimensão subjetiva da busca pelo conhecimento e do estabelecimento de possíveis inferências sobre os saberes de um grupo de indivíduos (YIN, 2005).

\footnotetext{
${ }^{5}$ Ressaltamos que não se trata de uma repetição literal do modelo das guildas, mas de uma apropriação crítica do trabalho cooperativo. Na proposta de Feitosa e Leite $(2011,2012)$ dominam as relações horizontais, de parceria e de aprendizado mútuo.

6 O termo "engajamento" representa "uma postula de filiação e participação ativa em uma determinada causa social, em especial, pondo-se a serviço de uma sociedade justa, igualitária e emancipatória” (FEITOSA; LEITE, 2011, p. 100).
} 
Adotamos como percurso metodológico a pesquisa-ação colaborativa (PIMENTA, 2005). A pesquisa-ação tem como atributo principal o pressuposto de que os sujeitos participantes compõem um grupo com metas comuns, orientados para um problema que emerge no contexto local no qual operam (BARBIER, 2002). Por sua vez, a pesquisa colaborativa tem por objetivo criar nas instituições de ensino uma cultura de análise das ações que são realizadas nesses espaços, com o intuito de possibilitar que os seus sujeitos, auxiliados pelos pesquisadores, reflitam sobre suas práticas e as transformem (PIMENTA, 2005).

Os dados foram coletados através de uma oficina ministrada pelos pesquisadores. Durante a oficina, os integrantes do grupo foram convidados a desenhar e colorir uma mandala ${ }^{7}$ que representasse sua concepção sobre as ações desenvolvidas pelo grupo de aprendentes ensinantes. Nesse momento fizemos a gravação de áudio das falas dos participantes, em gravador digital, a qual foi utilizada como fonte de dados primária na pesquisa. Destarte, também aproveitamos as próprias mandalas como fonte auxiliar de dados.

O grupo presente foi composto por nove integrantes, sendo quatro homens e cinco mulheres, com idade variando entre 20 e 50 anos de idade, identificados com nomes fictícios de pedras preciosas, a saber: Rubi, Diamante, Safira, Ametista, Topázio, Turmalina, Citrino, Ágata, Amazonita. Com essa designação representamos a metáfora de que a educação é uma montanha repleta de joias que podem ser lapidadas, como as pedras de um rio que ficam polidas com o atrito entre si ou através do trabalho conduzido pelo artista em seu atelier formador.

A água que leva as joias são os líquidos, amorosos (FREIRE, 1983), da reflexão, tolerância, diálogo e respeito à diversidade cultural. Certamente, não se trata de pensar, ipsis litteris, que os educandos são seres desprovidos de subjetividade; não podemos "lapidar" os nossos estudantes da mesma forma que um artesão afeiçoa uma pedra bruta ou pinta um quadro em branco. $\mathrm{Na}$ verdade, consideramos que o objeto de trabalho do educador são seres humanos (alunos e alunas) e, por conseguinte, os saberes dos professores carregam as marcas do ser humano.

Junto com essas joias, temos a participação/lapidação de um professor coordenador do grupo de pesquisa, responsável por sistematizar a organização das atividades. A esse integrante demos o nome de Diamante, pois esse mineral é utilizado na lapidação de outros tipos de minérios. Entretanto, é importante destacar, como ponderamos anteriormente, que, na medida em que o diamante lapida algo, ele é, ao mesmo tempo, tocado por esse e torna-se uma pedra diferente.

Posteriormente à oficina, realizamos a transcrição do material. Após essa etapa, os parceiros envolvidos na pesquisa foram convidados a analisar o material transcrito e, caso necessário, sugerir a alteração de algum discurso ${ }^{8}$.

Após diversas leituras dos dados coletados, foram destacadas as concepções dos informantes sobre o grupo, a partir das quais se procedeu à categorização dos dados. Buscamos por padrões semelhantes de respostas em relação à práxis realizada no grupo, bem como procuramos seus contraditórios, isto é, afirmações que, embora possam ser únicas, são relevantes para o entendimento da temática.

Para o procedimento de categorização, recorremos aos critérios apresentados por Silverman (2009), segundo os quais as categorias de organização e de análise devem apresentar: exaustão, exclusão mútua e objetividade.

Utilizamos para a análise do material coletado a estratégia "baseada em proposições teóricas” (YIN, 2005, p. 133), na qual a análise e a categorização dos dados primários são feitas tomando-se também os referenciais teóricos apresentados, em especial as Associações de

\footnotetext{
${ }^{7}$ Os modelos de mandalas usados para a elaboração da oficina foram retirados do sítio Coloriages.

8 Ainda nessa etapa, os partícipes foram convidados a autorizar a liberação dos seus discursos e mandalas para esta pesquisa, acordo formalizado pelo preenchimento de um termo de consentimento livre e esclarecido. Uma cópia dos dados (discursos e mandalas) ficou com os pesquisadores e os originais foram devolvidos aos seus respectivos produtores.
} 
Companheiros de Ofício (FEITOSA; LEITE, 2011, 2012). Yin (2005, p. 133) afirma que as proposições dariam "forma ao plano de coleta de dados e, por conseguinte, estabeleceriam a prioridade às estratégias analíticas relevantes". O autor chama de "proposição" os aspectos que levaram o pesquisador ao estudo, como, por exemplo, as revisões feitas na literatura ou observações prévias que o investigador fez em campo. Em nosso caso, escolhemos as categorias relacionadas à teoria apresentada por Feitosa e Leite (2011).

\section{"Florescer de novas perspectivas": o grupo de pesquisa na visão de seus integrantes}

A análise das falas e das mandalas (Figura 1) dos integrantes do referido grupo indica que eles concebem as atividades desenvolvidas como detentoras de grande possibilidade de ampliar os laços de amizade e de afeto, resultando, assim, numa ampliação das possibilidades de cooperação entre os partícipes.
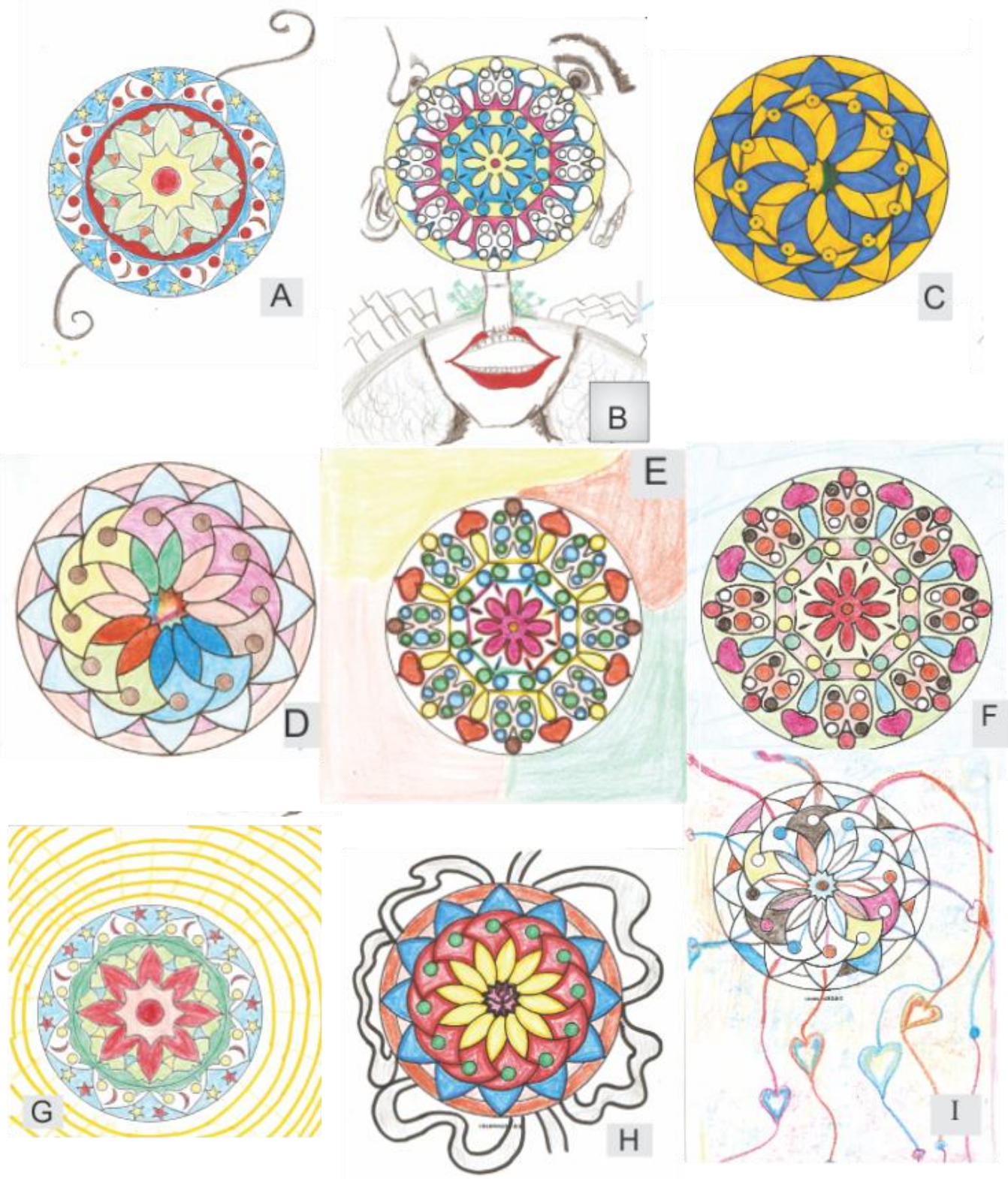

Figura 1: Mandalas coloridas pelos integrantes do grupo. (A) Turmalina; (B) Rubi; (C) Diamante; (D) Safira; (E) Ametista; (F) Citrino; (G) Ágata; (H) Amazonita; (I) Topázio. 
A colaboração é destacada como muito importante por alguns dos integrantes (Turmalina, Rubi e Diamante). Turmalina, por exemplo, ao fazer referência à sua mandala (Figura 1, A), explicita que sua individualidade está sempre em interação com seus colegas, formando uma espécie de teia tecida através das relações humanas dentro do grupo. Em suas palavras:

[...] eu coloquei várias cores, cores primas, exatamente pensando naquela perspectiva da construção, de poder vir ser mais, de poder vir a ser melhor, de uma coisa que está pra ${ }^{9}$ ser construída. E esses círculos eu desenhei como uma possibilidade de expansão, de crescimento, na perspectiva de poder ser melhor, de refletir sobre algumas coisas. E esse círculo também, de alguma forma, eu pensei representando cada um de nós, na sua individualidade, no seu universo de vivência e de experiência, que vão interagindo no espaço, como se fosse uma teia. (Turmalina).

Para Turmalina, as cores e os círculos geométricos de sua mandala representam possibilidade de desenvolvimento pessoal e profissional, isto é, uma "perspectiva de poder ser melhor". Em sintonia com esse discurso, Rubi adiciona uma boca em volta de sua "sedutora" mandala (Figura 1, B), indicando que, ao se alimentar (conceitual e espiritualmente) nesse espaço, existe a possibilidade de articulação e parceria não apenas dentro do GEAD mas também com outros grupos.

Minha interpretação é de uma boca muito sedutora. [...] e acho que entra no sentido do GEAD, de procurar alimentos conceituais e espirituais nesse espaço, nesse ambiente. [...] É uma questão de sedução, da nossa saída daqui e ter sedução para com os outros grupos num processo de ampliar nossas ideias com os outros grupos. (Rubi).

Seguindo a mesma perspectiva de colaboração, Diamante descreve o grupo como um espaço de "acolhimento". Esse partícipe enxerga grande valor nas interações que ocorrem no grupo, as quais geram uma "mudança permanente". Tal mudança, segundo ele, é o que permite a criação de novas ideias. Em sua percepção, na confraria de pesquisa há

[...] uma interação, e assim, o azul sai do amarelo e o amarelo sai do azul: é esse contínuo mudar, essa mudança permanente. E associando isso, a essa ideia, o GEAD é, acima de tudo, esse espaço utópico, um lugar que se faz a qualquer momento, mas que potencialmente traz esse acolhimento, esse vir a ser, que já é vir a ser. Eu acho que esse vir a ser é algo muito sedutor, porque ele está sempre alimentando o inédito, em certa medida. (Diamante).

Percebemos que a fala de Diamante porta uma perspectiva dialética sobre a interação dos partícipes do grupo e sobre as possibilidades formativas que ocorrem no mesmo. Ele representou sua visão em cores primas (Figura 1, C), notadamente azul e amarelo. Segundo seu discurso, essas cores/formas se entrelaçam continuamente, formando um arranjo mandálico que traz a potência da mutabilidade, de um "vir a ser, que já é vir a ser".

Outro participante que fez menção a essa perspectiva associativa entre o individual e o grupal foi Topázio. Em sua visão, no GEAD: “As pessoas vêm por interesses diversos, mas aqui acaba que a gente defende os interesses comuns também. Há um interesse individual, mas também há um coletivo". Para esse integrante, o grupo parece ser uma extensão do indivíduo. Seu discurso aponta para uma relação dinâmica entre o indivíduo e a sociedade, na qual estes são interdependentes, entendidos em uma determinação dialética de suas dimensões (FIGUEIREDO, 2007; LOUREIRO, 2006).

As concepções dos quatro partícipes citados (Turmalina, Rubi, Diamante e Topázio) indicam que a colaboração foi apontada como uma grande característica das atividades de pesquisa e estudo desenvolvidas pelo GEAD. Diante da referida percepção, podemos associar as atividades formativas que ocorrem no grupo ao que Feitosa e Leite (2011, p. 98) chamam de mutualismo, isto é, "reflexões-ações que beneficiem o grupo como um todo, pois todos são interdependentes". Dessa forma, teríamos um passo inicial para superar o individualismo, um dos feitios da sociedade capitalista e que gerou parte da fissura metabólica que encontramos

\footnotetext{
9 Os traços de oralidade de todos os informantes foram mantidos para representar, da forma mais aproximada possível, a forma original de suas falas.
} 
atualmente, isto é, uma segregação entre a sociedade e seu ambiente e entre os próprios humanos em sociedade.

Em outro trabalho, Feitosa e Leite (2012) indicam que as Associações de Companheiros de Ofício, segundo a proposta teórica, funcionariam como espaços de formação colaborativa e trariam como característica organizativa marcante o interclassismo, ou seja, o compartilhamento do mesmo status de direito entre seus companheiros. Diante da análise dos resultados, percebemos uma semelhança entre a proposta dos autores e a constituição que encontramos no GEAD.

Feitosa e Leite $(2011,2012)$ também apontam a interdisciplinaridade e a diversidade de ideias como aspectos marcantes, relevantes, das confrarias de ofício. Novamente, trazemos as falas dos integrantes do grupo para denotar outra semelhança entre os Companheiros de Ofício (FEITOSA; LEITE, 2012) e o que os partícipes do GEAD concebem sobre suas atividades. A esse respeito, Safira (Figura 1, D) é clara ao indicar que o grupo porta uma heterogeneidade de ideias:

Primeiro eu fiz bem colorido, colocando várias cores que se misturam, e assim, colocando quantidades diferentes e tonalidades, só no final aqui que é mais homogêneo, pra dizer que a contribuição do GEAD pra mim é essa diversidade de ideias e de sentimentos. E pra mim é muito bom isso pra mim. Colabora muito pra minha formação, pois eu acho que o GEAD [...] abre perspectivas para outras possibilidades. (Safira).

Outra integrante do grupo, chamada aqui de Ametista, acredita que nele existe uma diversidade de pontos de vista sobre a educação ambiental, o que, em sua visão, permite o aprendizado em grupo e gera várias "ideias pra gente trocar". Em suas palavras:

Eu coloquei a minha complexidade e a complexidade do GEAD, a diversidade de cores, as misturas, que cada um tem seu posicionamento, tem seu pensamento, da gente da discutindo, tem ideias pra gente trocar, e eu deixei uns espaços brancos pensando nisso: tem alguns conhecimentos, mas tem algumas coisas quero compartilhar com vocês, aprender mais de vocês. (Ametista).

Notamos que a fala de Ametista prima por expor a "diversidade de cores" que existem no grupo, como representado em sua mandala (Figura 1, E). Do ponto de vista da educação ambiental, a variedade de discursos sobre o ambiente e a sociedade é apontada como fundamental para a formação de educadores ambientais (CARVALHO, 2001; KAWASAKI; MATOS; MOTOKANE, 2006; TOZONI-REIS, 2002).

Ao adotar-se como um dos parâmetros dessa confraria de educadores a heterogeneidade de propostas, abre-se espaço para o diálogo entre os diversos pontos de vista da EA. Uma vez que se reconhece a existência de uma diversidade de concepções que compartilham o mesmo nome, educação ambiental, participar de um grupo de pesquisa que permite o compartilhar de visões sobre o tema torna-se relevante para a formação inicial e continuada desses educadores.

Outro participante, Citrino, indica que o grupo, como consequência dessa diversidade de ideias, está repleto de "sementes", isto é, integrantes, em diferentes estágios de maturação profissional, pessoal e acadêmica, dependendo de suas vivências. Em sua mandala, ele também representou uma flor ("atitudes") e algumas gotas (água). Ao explicitar o que representam essas imagens (Figura 1, F), ele afirmou:

Dentro do desenho, bem no centro, num vermelho bem encarnado [...] vai representar uma flor que representa um florescer de novas perspectivas, uma nova atitude. E essa flor que representa o GEAD está envolta por vários aspectos, por várias outras sementes, que são aquelas sementes que já estão no grupo há mais tempo, e outras que entraram agora e ainda vão se desenvolver nessa perspectiva da semeadura. E, essa flor, ela está entrando em contato com algumas gotículas aqui, algumas águas que vão tá regando e fazendo essa flor florescer, criar frutos e depois novas sementes. (Citrino).

Diante desse discurso, podemos apontar que Citrino acredita que existem diferentes níveis entre os companheiros do grupo, pois em suas palavras ele adverte que há "sementes que já estão no grupo há mais tempo, e outras que entraram agora e ainda vão se desenvolver". Da mesma forma que ocorria nas guildas medievais, que se estabeleciam como uma rede com 
vínculos múltiplos entre os indivíduos que as compunham, no grupo investigado parece haver diferentes níveis de experiência entre seus membros. Essa característica se assemelha ao modelo proposto por Feitosa e Leite (2011), do professor como um artista criativo, no qual defendem que nas corporações de ofício de docentes existe uma interação dos professores aprendizes mestres com os professores mestres mais experientes, ambos os tipos ensinando e aprendendo mutuamente.

Citrino também destaca o aprendizado em parceria que ocorre no GEAD, no qual seria possível "criar frutos e depois novas sementes". Esse membro representa o grupo como um lócus que permite o "florescer de novas perspectivas". Novamente, trazemos o trabalho de Feitosa e Leite (2012) para a discussão, pois esses autores postulam que nas Associações de Companheiros de Ofício os saberes seriam compartilhados entre os mestres e aprendizes, através da ajuda mútua e da dialógica. Ligando esse raciocínio ao discurso de Citrino, percebemos uma grande semelhança teórica, a saber: tanto no grupo de pesquisa como nos trabalhos de Feitosa e Leite $(2011,2012)$ os partícipes mais experientes na profissão compartilham seus saberes com os mais novos.

Também cabe destacar a fala proferida por outra integrante do grupo, que comentou a conotação política que a educação ambiental apresenta. Segundo ela, tal visão foi apresentada durante uma das reuniões do grupo.

[...] eu comecei [a mandala] com esse vermelho e esse verde, pois lembrei de uma coisa que ficou marcad[a] no meu primeiro encontro no GEAD, que foi a metáfora da melancia. [...] Eu fiquei pensando: dentro do vermelho tem várias tonalidades, várias formas de percepção, da mesma forma que do verde, da casca. (Turmalina).

Turmalina (Figura 1, A) ressalta que sua mandala representa uma de suas vivências no grupo, na qual ela ouviu a "metáfora da melancia", isto é, a analogia comparativa entre a EA e a fruta que contém o "verde da casca", indicando a conotação naturalista e convervacionista do movimento ambientalista, e traz por dentro o mesocarpo "vermelho" ${ }^{\text {, }}$, sugerindo que a EA possui um lado sociopolítico. Essa visão se coliga à chamada EA crítica (FIGUEIREDO, 2007) ou emancipatória (LOUREIRO, 2006).

Essa visão da EA como uma "melancia" permite avançar com relação às concepções não críticas (FIGUEIREDO, 2007), isto é, aquelas em que predominam os aspectos conservacionistas, biológicos, químicos e físicos da EA. Ao trabalhar a EA do ponto de vista da relação entre os aspectos sociopolítico-ambientais, o grupo mostra que os educadores ambientais são vistos como sujeitos históricos, portanto, estão imersos numa perspectiva social, política e cultural determinada.

Destarte, essa visão crítica da EA que o grupo apresenta gera em seus partícipes uma perspectiva de engajamento na luta por uma mudança, tanto no nível pessoal quanto no nível social. Para os educadores ambientais, essa vivência é interessante, pois acreditamos que, para superarmos as dificuldades do cotidiano "dos companheiros de ofício, é de grande estima a união entre reflexão-ação (práxis) como a força basilar hábil para transformar a educação no contexto do mundo atual" (FEITOSA; LEITE, 2011, p. 100). Desta feita, é possível deixar de considerar os docentes de maneira abstrata, como um grupo separado dos outros atores/autores sociais. no grupo:

Seguindo essa perspectiva de engajamento coletivo, Ágata discorre sobre sua participação

Tem sido uma coisa muito boa, porque é uma coisa além dos muros da universidade, além da nossa cabeça. [...] O verde são as ideias pra amadurecer, tanto minha quanto nossas. O vermelho simboliza a paixão pelo que a gente faz, esperanças e metas, e a vontade de mudar. (Ágata).

Analisando essa passagem, bem como a mandala de Ágata (Figura 1, G), notamos que a integrante concebe de forma positiva as atividades do grupo, em especial o fato de ser "uma coisa além dos muros da universidade". Ela parece reconhecer a responsabilidade que a pesquisa na

${ }^{10}$ Esse vermelho é uma referência às cores das bandeiras que os partidários dos partidos de base marxista carregam, demonstrando sua filiação às ideias socialistas ou comunistas. 
universidade possui para com a sociedade, pois, diante de um país como o nosso, com as severas desigualdades socioambientais, o saber acadêmico pode auxiliar na mudança de pensamento e da práxis dos sujeitos. Destarte, Ágata mostra que os integrantes do grupo, inclusive ela mesma, possuem "ideias pra amadurecer", isto é, ela vê a produção de saberes acadêmicos como algo inacabado. Outro ponto digno de nota é a ênfase que a partícipe dá à "vontade de mudar".

Da mesma forma que Ágata, sua companheira Amazonita destaca em sua mandala (Figura 1, H) que acha o grupo relevante para a sua formação, concebendo-o como um lócus de transformação. Vejamos uma passagem de seu discurso durante a oficina:

Não tem como separar o GEAD de mim. Eu encaro o GEAD como um local de formação, de transformação. [...] E, assim, eu tô bem no centro, mas eu estou também ao redor. Mostra o meu envolvimento, eu me sinto altamente entrelaçada com o GEAD. Comprometida, essa é a palavra. (Amazonita).

Amazonita demonstra estar "comprometida" com as vivências no grupo de pesquisa. Novamente, percebemos a forte relação entre os integrantes dessa confraria, pois a integrante descreveu essa interação humana como "entrelaçada". A esse respeito, Tozoni-Reis (2002) indica que as reflexões sobre a prática dos educadores ambientais devem ser realizadas com o coletivo dos sujeitos envolvidos nos processos educativos e, sobretudo, devem ter uma função política e crítica.

Topázio, por sua vez, ao falar de sua mandala (Figura 1, I), destacou em outra fala: "Eu gosto muito de participar do GEAD. [...] Eu aprendo muito com vocês". Para esse partícipe, o grupo de pesquisa é um local onde existe o aprendizado em parceria, havendo um processo de desenvolvimento humano através de reflexões-ações que beneficiam o grupo como um todo.

É possível deduzir dessas falas/diálogos que há uma percepção/reconhecimento do grupo aprendente nesse processo individual/coletivo de superar diferentes/iguais na costura de um ser mais (FREIRE, 1983). Constatamos que efetivamente há um contributo indiscutível do grupo para os indivíduos que o constituem e que lhe dão sentido, significado e existência. $O$ grupo se torna um ente que agrega e potencializa os indivíduos, de modo que sejam mais que indivíduos isolados, formando uma teia epistêmica potencializadora de um crescimento do grupo, dos que o constituem.

\section{Considerações Finais}

Chegamos a este ponto no qual podemos buscar finalizar temporariamente este trabalho. Lembramos que esta pesquisa buscou investigar como os integrantes do GEAD, grupo de pesquisa/estudo em educação ambiental, concebem as experiências formativas vivenciadas no grupo.

Diante dos dados apresentados nesta pesquisa, percebemos que o grupo de pesquisa GEAD foi visto pelos seus membros como uma possibilidade de formação humana colaborativa, estimulando a criatividade, a diversidade de pontos de vista e os laços de companheirismo. Ao meditarmos sobre os discursos dos participantes do GEAD, notamos que, ao estudarem/pesquisarem em conjunto, os atores/autores ${ }^{11}$ sociais partícipes do grupo podem desenvolver seus saberes (individuais e coletivos), criando um campo de possibilidades formativas.

Nesse sentido, esses resultados vão ao encontro dos trabalhos de vários autores, os quais indicam que o estudo/pesquisa feito em grupos pode contribuir de forma positiva para a formação dos profissionais (BALDINO, 2001; DE MASI, 2007; FOGAGNOLI; PIRES; SILVA, 2008; PEREIRA et al., 2011). Hillebrand (2001) apresenta uma confraria de professores e indica que o estudo em grupo funciona como uma estratégia de educação continuada desses

11 Utilizamos o termo autores, além do vocábulo ator social, porque concebemos que, além de atuarem na interpretação de textos elaborados por terceiros, os sujeitos das pesquisas são potencialmente produtores de seus próprios roteiros curriculares. 
docentes. Esses autores indicam que os grupos de pesquisa podem ser considerados como locais de aprendizagem para alunos e professores e também local de produção de conhecimentos.

Seguindo o ponto de vista apresentado por Feitosa e Leite $(2011,2012)$, encontramos várias semelhanças entre o grupo investigado e o que os autores denominaram Associações de Companheiros de Oficio. Entre as características semelhantes encontramos: cooperação, interclassismo, diversidade, engajamento e busca pela transformação social. Desta feita, acreditamos que o GEAD parece ser um exemplo concreto da proposta dos professores-artistas de Feitosa e Leite. As atividades cooperativas que foram destacadas pelos integrantes do grupo foram relevantes para a formação desses educadores ambientais.

Do ponto de vista da educação ambiental, as ações-reflexões que ocorreram no GEAD foram o "florescer de novas perspectivas" para muitos de seus integrantes. Segundo os companheiros do grupo, a diversidade de propostas existentes no grupo permite a aquisição de uma visão mais abrangente sobre o tema, possibilitando avançar com relação às propostas mais conservadoras da educação ambiental.

Destarte, foi destacada nas falas dos partícipes a perspectiva de EA Crítica, com base na metáfora da "melancia", isto é, uma EA que é, ao mesmo tempo, verde (conservacionista e biologizante) e vermelha (sociopolítica e comunista). Essas concepções também foram representadas em mandalas, durante a oficina, as quais funcionaram como ferramentas reflexivas, resgatando a vivência do grupo, além de possibilitarem a análise de dados relacionados às concepções subjetivas dos atores/autores investigados.

Tomando como base os resultados desta pesquisa, inferimos que é relevante ampliar os espaços de interação cooperativa nas instituições de ensino superior, em especial na constituição de grupos de pesquisa/estudo/ação relacionados à temática da EA. Dessa forma, será possível arquitetar relações entre graduandos, pós-graduandos e professores pesquisadores, abrindo espaço para o desenvolvimento de educadores ambientais que aliem a pesquisa com a práxis transformadora, através de um aprendizado cooperativo entre noviços e profissionais experientes. Não menos importante é a formação de confrarias multidisciplinares, como a encontrada no GEAD, que são formadas por partícipes de várias áreas da academia, pois essa diversidade pode proporcionar o desenvolvimento de ações interdisciplinares, algo bem relevante para a formação de educadores ambientais, para o reconhecimento do verde como uma mistura entre o amarelo (sabedoria) e o azul (amor).

\section{Referências}

BALDINO, Roberto R. Grupos de pesquisa-ação em educação matemática. Bolema, Rio Claro, v. 14, n. 15, p. 83-103, 2001.

BARBIER, René. A Pesquisa-Ação. Brasília: Liber Livro, 2002.

CARVALHO, Isabel Cristina M. Qual educação ambiental? Elementos para um debate sobre educação ambiental e extensão rural. Agroecol. e Desenv. Rur. Sustent., Porto Alegre, v. 2, n. 2, p. 43$51,2001$.

COLORIAGES. Disponível em: < http://www.coloriages.biz/>. Acesso em: 18 jul. 2012.

DE MASI, Domenico (Org.). A emoção e a regra: os grupos criativos na Europa de 1850 a 1950. 9. ed. Rio de Janeiro: José Olympio, 2007.

FEITOSA, Raphael A.; LEITE, Raquel Crosara M. O trabalho e o saber docente: construindo a Mandala do professor artista-reflexivo. Rio de Janeiro: Câmara Brasileira do Jovem Escritor, 2011. 
FEITOSA, Raphael A.; LEITE, Raquel Crosara M. A formação de professores de Ciências baseada numa associação de companheiros de ofício. Ensaio: Pesq. em Educ. em Ciências [online], Belo Horizonte, v. 14, p. 35-50, 2012. Disponível em: < http://www.foco.fae.ufmg.br/viienpec/index.php/enpec/viienpec/paper/viewFile/626/254>. Acesso em: 18 jul. 2012.

FIGUEIREDO, João Batista A. Educação Ambiental Dialógica: as contribuições de Paulo Freire e da cultura sertaneja nordestina. Fortaleza: Edições UFC, 2007. (Coleção Diálogos Intempestivos, 43).

FOGAGNOLI, Alissianny H.; PIRES, Antonio Geraldo M. G.; SILVA, Morgana C. O grupo de pesquisa de formação de professores de educação física: a (re)significação da iniciação científica. Nuances, Presidente Prudente, v. 15, n. 16, p. 65-79, 2008.

FOSTER, John B. A Ecologia de Marx: materialismo e natureza. Rio de Janeiro: Civilização Brasileira, 2005.

FRANCHI, Maria Tereza. Mandalas: a busca do equilíbrio. São Paulo: Berkana, 2002.

FREIRE, Paulo. Pedagogia do oprimido. 13. ed. Rio de Janeiro, RJ: Paz e Terra, 1983.

HILLEBRAND, Vicente. Grupos de estudo: uma estratégia de educação continuada de professores. Ciências \& Letras, Porto Alegre, n. 29, p. 145-167, 2001.

KAWASAKI, Clarice S.; MATOS, Mauricio dos Santos; MOTOKANE, Marcelo T. O perfil do pesquisador em educação ambiental: elementos para um estudo sobre a constituição de um campo de pesquisa em educação ambiental. Pesquisa em Educação Ambiental, São Carlos, v. 1, n. 1, p. 111-140, 2006.

KRAHL, Mônica; SOBIESIAK, Eliane F.; POLETTO, Denise S.; CASARIN, Rodrigo G.; KNOPF, Luciane A.; CARVALHO, Juliana; MOTTA, Liriane A. Experiência dos acadêmicos de enfermagem em um grupo de pesquisa. Rev. Bras. Enferm., Brasília, v. 62, n. 1, p. 146-150, 2009.

LOUREIRO, Carlos Frederico B. Complexidade e dialética: contribuições à práxis política e emancipatória em educação ambiental. Educação \& Sociedade, Campinas, v. 27, n. 94, p. 131-152, 2006.

MARX, Karl. Manuscritos Econômico-Filosóficos. São Paulo: Boitempo, 2004.

MOCELIN, Daniel G. Concorrência e alianças entre pesquisadores: reflexões acerca da expansão de grupos de pesquisa dos anos 1990 aos 2000 no Brasil. RBPG, Brasília, v. 6, n. 11, p. 35-64, 2009.

PEREIRA, Milca S.; RIBEIRO, Luana Cássia M.; MENDONÇA, Katiane M.; TIPPLE, Anaclara Ferreira V.; SOUZA, Adenícia Custódia S.; PALOS, Marinésia Aparecida do P.; BARRETO, Regiane Aparecida dos S. S. Grupo de Pesquisa em Enfermagem na Prevenção e Controle de Infecções: 20 anos de contribuições. Rev. Eletr. Enf., Goiânia, v. 13, n. 1, p. 124-129, 2011. Disponível em: < http://www.fen.ufg.br/revista/v13/n1/v13n1a14.htm $>$. Acesso em: 20 jul. 2012. 
PIMENTA, Selma G. Pesquisa-ação crítico-colaborativa: construindo seu significado a partir de experiências com a formação docente. Educação e Pesquisa, São Paulo, v. 31, n. 3, p. 521-539, 2005.

PINHEIRO, José Q. O lugar e o papel da Psicologia Ambiental no estudo das questões humanoambientais, segundo Grupos de Pesquisa Brasileiros. Psicologia USP, v. 16, n. 1-2, p. 103-113, 2005.

PRADO, Shirley Donizete; SAYD, Jane Dutra. A pesquisa sobre envelhecimento humano no Brasil: pesquisadores, temas e tendências. Ciênc. saúde coletiva, Rio de Janeiro, v. 9, n. 3, 2004. Disponível em: <http://www.scielo.br/scielo.php?script=sci_arttext\&pid=S1413$81232004000300027 \& \operatorname{lng}=$ en\&nrm=iso $>$. Acesso em: 20 jul. 2013.

QUEIROZ, Glória Regina P. C. Processos de formação de professores artistas-reflexivos de Física. Educaşão \& Sociedade, Campinas, ano XXII, n. 74, p. 97-119, 2001.

RAMOS, Fernando S. Forma e arquétipo: um estudo sobre a Mandala. Dissertação (Mestrado) Universidade Estadual de Campinas, Instituto de Artes, Campinas, 2006.

RAPINI, Márcia S. Interação Universidade-Empresa no Brasil: Evidências do Diretório dos Grupos de Pesquisa do CNPq. Estud. econ., São Paulo, v. 37, n. 1, p. 211-233, 2007.

RIBEIRO, Miguel A. Algumas considerações sobre grupos de pesquisa: agricultura e desenvolvimento regional - relatos de experiências. Campo-Território, Uberlândia, v. 2, n. 3, p. 8992, 2007.

RICARDO, Maria Manoel C. A emergência do sindicalismo docente na imprensa do Estado Novo - os grupos de estudo do pessoal docente do ensino secundário (GEPDES). Rev. Lusófona de Educaşão, Lisboa, n. 4, p. 133-138, 2004.

TOZONI-REIS, Marília Freitas de Campos. Formação dos educadores ambientais e paradigmas de transição. Ciência \& Educação, Bauru, v. 8, n. 1, p. 83-96, 2002.

YIN, Robert K. Estudo de caso: planejamento e métodos. 3. ed. Porto Alegre: Bookman, 2005.

Artigo recebido em 25/02/2013

Artigo aprovado em 05/06/2013 